Conclusion: Interviewed patients seemed to prefer continuation of IA during an infection if possible. The concern of disease flare might form a barrier for temporary interruption, this is in line with a previous study, showing that RA patients fear disease flare after dose reduction ${ }^{2}$.

REFERENCES:

[1] Singh JA, Cameron C, Noorbaloochi S, Cullis T, Tucker M, Christensen R, et al. Risk of serious infection in biological treatment of patients with rheumatoid arthritis: a systematic review and meta-analysis. Lancet. 2015;386(9990):258-65.

[2]Verhoef LM, Selten EMH, Vriezekolk JE, de Jong AJL, van den Hoogen FHJ, den Broeder AA, et al. The patient perspective on biologic DMARD dose reduction in rheumatoid arthritis: a mixed methods study. Rheumatology. 2018;57(11):1947-55. Disclosure of Interests: Merel Opdam Grant/research support from: has received research grants (to the institution) from Gilead, L.M. Verhoef: None declared, Johanna Vriezekolk: None declared, Bart van den Bemt: None declared, Alfons den Broeder Grant/research support from: has received consultancy honoraria, congress invitations and research grants (to the institution) from Abbvie, Amgen, Cellgene, Roche, Biogen, Lilly, Novartis, Celltrion Sanofi, Gilead. Is coinventor on a rituximab related patent (pending)

DOI: 10.1136/annrheumdis-2021-eular.2280

\section{POS1486-HPR DAILY ACTIVITY IMPAIRMENT IS MEDIATED BY BOTH ORAL DRYNESS AND ORAL HEALTH RELATED QUALITY OF LIFE IN PATIENTS WITH PRIMARY SJÖGREN'S SYNDROME}

Y. Yenisoy ${ }^{1}$, A. Kapusuz ${ }^{1}$, E. N. Çakır ${ }^{1}$, K. Abacar ${ }^{2}$, İ. Tatlı ${ }^{3}$, F. Türe-Özdemir ${ }^{3}$, M. Yay ${ }^{4}$, Ü. Karaçaylı ${ }^{5}$, N. Inanc ${ }^{2}$, H. Direskeneli ${ }^{2}$, G. Mumcu ${ }^{6}{ }^{1}$ Marmara $^{1}$ University, Institute of Health Sciences, Istanbul, Turkey; ${ }^{2}$ Marmara University, Division of Rheumatology, Istanbul, Turkey; ${ }^{3}$ Marmara University, Department of Hematology and Immunology, Istanbul, Turkey; ${ }^{4}$ Mimar Sinan Fine Arts University, Department of Statistics, Istanbul, Turkey; ${ }^{5} \mathrm{Health}$ Sciences University, Department of Oral and Dental Surgery, Ankara, Turkey; ${ }^{6}$ Marmara University, Department of Health Management, Istanbul, Turkey

Background: Both oral functions and oral health-related quality of life (OHRQoL) are poorly affected by low salivary flow rate in patients with primary Sjögren's syndrome (pSS).

Objectives: The aim of the study was to evaluate the effects of oral dryness and OHRQoL on daily life in patients with primary Sjögren's syndrome (pSS).

Methods: In this cross-sectional study, 86 patients with pSS (M/F: 5/81; mean age: $52.4 \pm 11.6$ years) were included. The data were collected by clinical examination and a questionnaire regarding patient-reported outcome measures (PROMs). Patient filled PROMs regarding Oral Health Impact Profile-14 (OHIP14) for OHRQoL, Work Productivity and Activity Impairment scale (WPAI) for Daily life and the EULAR Sjogren's Syndrome Patient Reported Index (ESSPRI) for their symptoms. Unstimulated whole saliva flow rates (U-WSFR) of patients were calculated as $\mathrm{ml} / \mathrm{min}$. Increases in PROMs and decreases in U-WSFR reflected poor conditions. After preliminary analysis, a mediation analysis was used to evaluate the relations among variables.

Results: WPAI-Daily activity impairment score was higher in patients with low U-WSFR $(\leq 0,1 \mathrm{~m} / \mathrm{min})$ than the others $(67 \pm 29,8$ vs $52,5 \pm 28,6)(p=0.042)$. Both U-WSFR $(0,43 \pm 0,57 \mathrm{ml} / \mathrm{min})$ and ESSPRI-Dryness score $(6.31 \pm 2.71)$ were correlated with scores of OHIP-14 (25,96 $\pm 17,13)(r:-0,38 p=0.000 ; r: 0,37 p=0.000)$ and WPAl-Daily activity impairment $(57,96 \pm 29,71)(r:-0,36 p=0.004 ; r: 0,53 p=0.000)$. Moreover, scores of ESSPRI-Pain $(5,16 \pm 3,12)$ and ESSPRI-Fatigue $(5,41 \pm 2,97)$ were also related to WPAI-Daily activity impairment score ( $r: 0,41 p=0.001 ; r: 0,49 p=0.000$, respectively). In the mediation analysis, WPAI-Daily activity impairment score $(57.9 \pm 29.7)$ was directly mediated by ESSPRI-Dryness score $(\mathrm{p}=0.0010)$ and indirectly mediated by OHIP-14 score $(25.9 \pm 17.1)(\mathrm{p}=0.0357)$. After mediation analysis, a bootstrap analysis with 5000 replications was applied to estimate the mediation effect to generate $95 \% \mathrm{Cl}$. Percentile bootstrap of OHIP-14 score was found to be an effective mediator for Daily activity impairment based on 5000 bootstrap samples. Conclusion: Both oral dryness and poor OHRQoL in patients with pSS affected daily activity impairment. Therefore, the patients' needs for improving oral health were critical components of treatment plans to improve the daily activity of SjS patients. Disclosure of Interests: None declared DOI: 10.1136/annrheumdis-2021-eular.3013

\section{HPR Service developments, innovation and eco- nomics in healthcare}

\section{POS1487-HPR NEXT-GENERATION ONLINE TELEMEDICINE SYSTEM UTILIZING MIXED REALITY FOR RHEUMATOID ARTHRITIS}

S. Y. Kawashiri ${ }^{1}$, F. Nonaka ${ }^{2}$, S. Chiba ${ }^{3}$, T. Honda ${ }^{4}$, T. Nakajima ${ }^{4}$, T. Ishikawa ${ }^{3}$, A. Kawakami ${ }^{5}{ }^{1}$ Nagasaki University Graduate School of Medical Sciences, Departments of Community Medicine, Nagasaki, Japan; ${ }^{2}$ Nagasaki University
Graduate School of Medical Sciences, Department of Island and Community Medicine, Nagasaki, Japan; ${ }^{3}$ Microsoft Japan Co., Ltd., N/A, Tokyo, Japan; ${ }^{4}$ Rocket Studio, Inc., N/A, Tokyo, Japan; ${ }^{5}$ Nagasaki University Graduate School of Medical Sciences, Departments of Immunology and Rheumatology, Nagasaki, Japan

Background: Telemedicine can be performed using a conventional videophone or web conferencing system. Then, joint lesions can only be observed and inferred from two-dimensional images, and it is difficult to perform accurate joint assessments, which is essential for the management of rheumatoid arthritis (RA).

Objectives: To develop the next-generation online telemedicine system utilizing mixed reality for RA.

Methods: We have developed a system that can assess joints accurately in three-dimensions images in real-time, using Azure Kinect DK (depth sensor)/ HoloLens 2 (headset), which are mixed reality technologies, and Teams (online interview/chat) provided by Microsoft. Furthermore, by applying artificial intelligence (Al), we plan to implement additionally to this system 1) a function to quickly catch and automatically evaluate the patient's anxiety and changes in facial expressions at the time of examination, 2) a function to record dialogue with the patient in chronological order, 3) a function to support the detection of swollen joints, and 4) function to automatically analyze the questionnaire.

Results: This system remotely connects a rheumatologist in the Nagasaki University Hospital (Nagasaki City, urban area) and a patient with RA and a non- rheumatologist in the Goto Central Hospital (Goto Island, rural area). A three-dimensional hologram of the patient's hand projected in front of a rheumatologist. Using this system, we are able to evaluate joints more accurately than using a conventional videophone or web conferencing system.

Conclusion: It is expected that this system will enable remote medical care specializing in rheumatology, which is standardized at a high level even in areas without rheumatologists such as remote islands and remote areas. This system remotely connects Nagasaki City and Goto Island, but due to the performance of the system, it is not limited to these areas and it is possible to connect rheumatologists to any area that can be connected to the network. It is also effective for the purpose of avoiding the risk of infection during long-distance hospital visits under the epidemic of COVID-19 infection.

REFERENCES:

[1] Mov Disord. 2020;35:1719-1720.

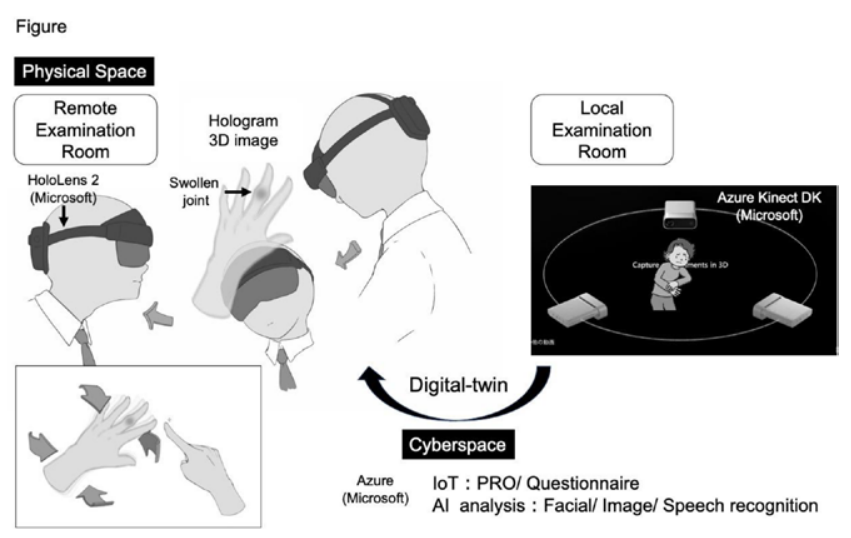

Disclosure of Interests: Shin-ya Kawashiri Speakers bureau: Speaker fees from AbbVie, Asahi Kasei, Astellas, Chugai, Eisai, Eli Lilly, Mitsubishi Tanabe, Novartis, and ONO., Grant/research support from: Research grants from Pfizer., Fumiaki Nonaka: None declared, Shinji Chiba: None declared, Tomoyuki Honda: None declared, Tomohiko Nakajima: None declared, Tomoyuki Ishikawa: None declared, Atsushi Kawakami Speakers bureau: Speaker fees from AbbVie, Actelion, Asahi Kasei, Astellas, Boehringer Ingelheim, Celltrion, Chugai, Daiichi Sankyo, Eisai, Eli Lilly, GSK, Janssen, Kowa, MedPeer, Mitsubishi Tanabe Novartis, ONO, Pfizer, Taisho, and Takeda., Grant/research support from: Grants and research support from AbbVie, Actelion, Asahi Kasei, Astellas, AYUMI, Boehringer Ingelheim, Bristol-Myers Squibb, Celltrion, Chugai, Daiichi Sankyo, Eisai, Eli Lilly, Kyowa Hakko Kirin, MSD, Neopharma, Novartis, ONO, Sanofi, Taisho, Takeda Science Foundation, and Teijin DOI: 10.1136/annrheumdis-2021-eular.1029

\section{POS1488-HPR CAN A SPECIALIST NURSE LEAD A COMPREHENSIVE OSTEOPOROSIS SERVICE WITH REMOTE SUPERVISION - AN INNOVATIVE CONCEPT}

D. Masieh ${ }^{1}$, J. Begum ${ }^{1}$, J. Fourmy ${ }^{1}$, M. K. Nisar ${ }^{1} .{ }^{1}$ Luton and Dunstable University Hospital, Rheumatology, Luton, United Kingdom

Background: Specialist services traditionally rely on a consultant to lead a multidisciplinary team and provide patient facing activities. However, demand 